\title{
Modelling of Selective Laser Melting Process of Quartz Glass at Elevated Temperatures
}

\author{
M.A. Gridnev ${ }^{1, *}$, R.S. Khmyrov ${ }^{1}$, and A.V. Gusarov ${ }^{1}$ \\ ${ }^{1}$ Moscow State University of Technology “STANKIN”, RU-127055, Moscow, Russia
}

\begin{abstract}
Selective 1 aser melting (SLM) to $d$ ate is the method of additive manufacturing allowing fabricating products from pow der layer-by-layer a ccording to a $3 \mathrm{D}$ model. However, when applying this method to fragile materials, $\mathrm{p}$ arts crack while fabricating $\mathrm{d}$ ue $\mathrm{t} \mathrm{o} \mathrm{h}$ igh $\mathrm{t}$ emperatures. $\mathrm{Q}$ uartz $\mathrm{g}$ lass i s a promising material $\mathrm{f}$ or fabricating products by S LM w ithout $\mathrm{c}$ racks due to a low thermal e xpansion. However, $q$ uality o f $\mathrm{f}$ abricated material differs from the fused cast ones. This article aims to test the method of SLM with preheating to improve the $\mathrm{m}$ aterial $\mathrm{q}$ uality. Experiments o $\mathrm{n} \mathrm{s}$ ingle $\mathrm{t}$ rack f ormation i $\mathrm{n} \mathrm{S} \mathrm{LM} \mathrm{ar} \mathrm{e} \mathrm{an} \mathrm{alysed} \mathrm{b} \mathrm{y} \mathrm{modelling} \mathrm{t} \mathrm{he} \mathrm{co} \mathrm{upled}$ processes of he at $\mathrm{t}$ ransfer a nd pow der $\mathrm{c}$ onsolidation i $\mathrm{t}$ he 1 aser-interaction $\mathrm{z}$ one. The mathematical model is validated by the experiments. It is shown that the preheating can i mprove the material quality an $\mathrm{d}$ increase the process productivity but overheating may result in undesirable crystallization.
\end{abstract}

\section{Introduction}

The e merging $3 \mathrm{Dp}$ rinting $\mathrm{t}$ echnologies $\mathrm{c}$ an $\mathrm{b} \mathrm{e}$ advantageous for manufacturing $\mathrm{c}$ omponents o f gl ass. They do not require fabrication of exact molds necessary for die pressing of optical elements and can be applied to manufacture $\mathrm{p}$ arts of co mplicated s hape, f or ex ample hollow e lements that a re difficult to fabricate b y conventional $p$ rocesses 1 ike die $p$ ressing [1]. Selective laser melting ( SLM) is a $\mathrm{n}$ a dditive manufacturing (3D printing) pr ocess c onsisting i n 1 ayer-by-layer consolidation of a powder bed by a scanning laser beam that fuses powder particles together to form a solid part. Successful application of this material is demonstrated in specialized literature. Mat erial does not co ntain cracks, however, pores remain inside the fused material [2]. In addition, th e a uthors o $\mathrm{ft}$ he a rticle [ 3] $\mathrm{p}$ redict th at consolidation $\mathrm{c}$ an be i mproved pr ovided that s ample heating o ccurs while 1 aser $p$ rocessing. The $S$ LM was successively ap plied t o b orosilicate [4], s oda-lime [5], and quartz [6] glass. The advantages of the process are flexibility a nd high $\mathrm{p}$ recision. $\mathrm{T}$ he $\mathrm{d}$ isadvantages a re residual por osity a nd stresses. In S LM, a por tion of a powder bed is generally exposed to the laser beam for a fraction of a millisecond [3]. It can be insufficient for complete consolidation of powder and result in excessive residual porosity. The residual stresses arise because of a highly non-uniform temperature distribution in the laserinteraction $\mathrm{z}$ one, which 1 aunches $\mathrm{t}$ hermo-mechanical processes [7].

Quartz glass i sap romising material for S LM because of e xtremely 1 ow thermal e xpansion. T hat is why it doe $\mathrm{s}$ not $\mathrm{c}$ rack i $\mathrm{nthe} \mathrm{c}$ onditions of a strong thermal shock at la ser processing [6]. Consolidation of quartz $\mathrm{g}$ lass po wder i s c ontrolled by $\mathrm{v}$ iscous $\mathrm{f}$ low a $\mathrm{t}$ coalescence of molten powder particles [3].
Unfortunately, the viscosity of quartz glass is rather high even at elevated $t$ emperatures [8]. That is why the residual porosity can be unsatisfactory [3]. To reduce the porosity, one can reduce the scan speed at SLM [3]. This extends the thermal cycle, and thus increases the extent of consolidation. The disadvantage of such an approach is decreasing the productivity that is proportional to the scan speed. Another drawback is a strong non-uniformity of pore distribution in the laser-interaction zone. Even if the central domain is free of pores, a $\mathrm{h}$ igh porosity can be o bserved in the p eriphery of the heat af fected zo ne where $t$ he $t$ emperature $i \mathrm{~s} l$ ower an $\mathrm{d} t$ he $\mathrm{v}$ iscosity i s greater [3]. To a ttain a low and more uniform porosity and increase the productivity of SLM, it was proposed to apply a $p$ reheat [3]. The pr eheat i s maintaining the working zo ne o $\mathrm{ft}$ he $\mathrm{S} \mathrm{LM} \mathrm{m}$ achine at an el evated temperature $d$ uring $t$ he whole $p$ rocess. I $t$ was successfully ap plied to o ther materials, for ex ample to reduce cracking at SLM [9].

The $p$ resent work ai ms $t$ o $t$ est ex perimentally $t$ he influence of p reheating on S LM of quartz glass and to model the $\mathrm{c}$ oupled phy sical processes of $\mathrm{h}$ eat $\mathrm{t}$ ransfer and powder consolidation in the laser-interaction zone at SLM. The comparison o $\mathrm{ft}$ he experiments with the modelling i s u seful t o a nalyze t he i nfluence of SLM process $\mathrm{p}$ arameters $\mathrm{o} \mathrm{n}$ he $\mathrm{q}$ uality $\mathrm{o} f \mathrm{t}$ he $\mathrm{r}$ esulting material.

\section{Model and experiment}

\subsection{Mathematical model}

This work uses a mathematical model of laser-influence zone o $\mathrm{n}$ a $\mathrm{l}$ ayer o f q uartz $\mathrm{g}$ lass $\mathrm{p}$ owder at $\mathrm{d}$ ifferent process $p$ arameters of $s$ elective $l$ aser melting ( such a $s$

Corresponding author: Gridnev.M@stankin.ru

(c) The Authors, published by EDP Sciences. This is an open access article distributed under the terms of the Creative Commons Attribution License 4.0 
laser power, scanning speed, layer thickness and preheat temperature). Heat transfer is calculated in this model by the following equation:

$$
\partial H / \partial t=\nabla \cdot\left(\lambda_{e} \cdot \nabla T\right)+u \cdot \partial H / \partial x
$$

where $H$ is th e v olumetric e nthalpy, $\lambda e$ the ef fective thermal conductivity, $\nabla$ the nabla operator, $t$ the time, $T$ the temperature, $\mathrm{u}$ the scanning speed, $x$ the longitudinal coordinate. Figure 1 shows scanning process.

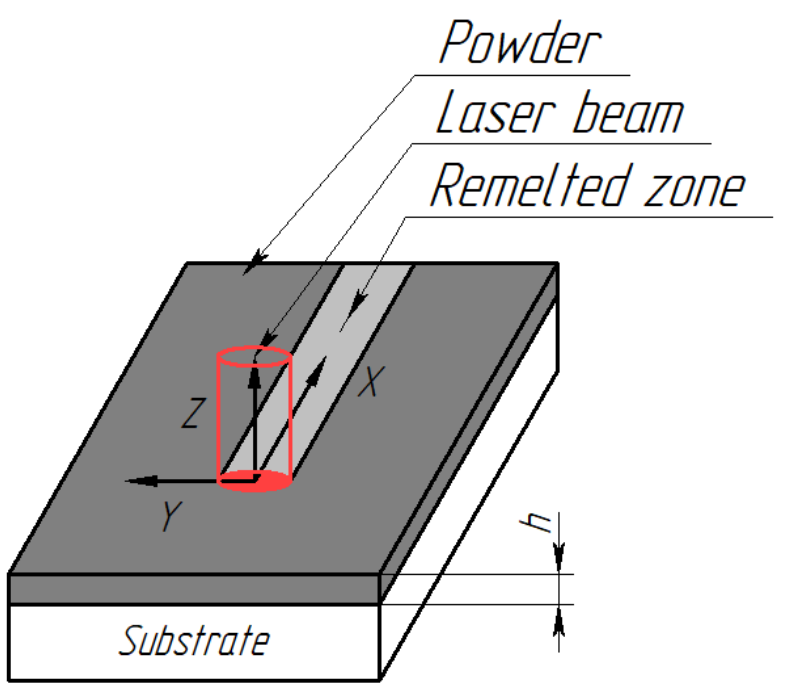

Fig. 1. Scanning process

Also e nthalpy is $\mathrm{r}$ elated with te mperature $\mathrm{b} y$ the following equation $[2+]$ :

$$
H=(1-\varepsilon) C_{p} T
$$

where $\varepsilon$ is the porosity equal to the volume fraction of the gas phase, and $C_{p}$ the volumetric specific heat.

Effective $\mathrm{t}$ hermal $\mathrm{c}$ onductivity is $\mathrm{c}$ alculated $\mathrm{b} \mathrm{y} t$ he following equation [3]:

$$
\lambda_{e}=\lambda_{s} \xi(1-\varepsilon) N / \pi
$$

where $\lambda_{s}$ is the thermal conductivity of solid phase, $N$ the average co ordination number, $\xi=a / D$ the c onsolidation degree meaning that the softened particles of fused silica behave like the droplets of vi scous liquid. They tend to coalesce as shown in Fig. 2. The extent of coalescence is characterised by neck diameter $a$. The ki netics of neck growth between two spherical particles of diameter $D$ is estimated as [3] calculated by the following equation [3]:

$$
\left(\partial \xi^{2}\right) / \partial t=3 \delta /(\eta D)
$$

where $D$ is the particle diameter, $\delta$ the s urface tension coefficient, $\eta$ the $\mathrm{d}$ ynamic viscosity. T he ef ficiency of this model h as b een d emonstrated in R ef. [3] a nd ha $\mathrm{s}$ been proven with our experiments.

The $\mathrm{m}$ athematical model co nsiders 1 aser $\mathrm{r}$ adiation influence o $\mathrm{n}$ a single 1 ayer an $\mathrm{d} t$ he $\mathrm{s}$ ubstrate $\mathrm{b}$ ecause every single layer becomes substrate for previous ones in the $t$ echnology of S LM. S canning of $t$ he surface $b$ y a laser beam occurs in a straight line at a constant speed $u$. The thermal conditions of laser scanning can be different for in itial stages of c onsolidation, h owever, e ventually all processes become steady.

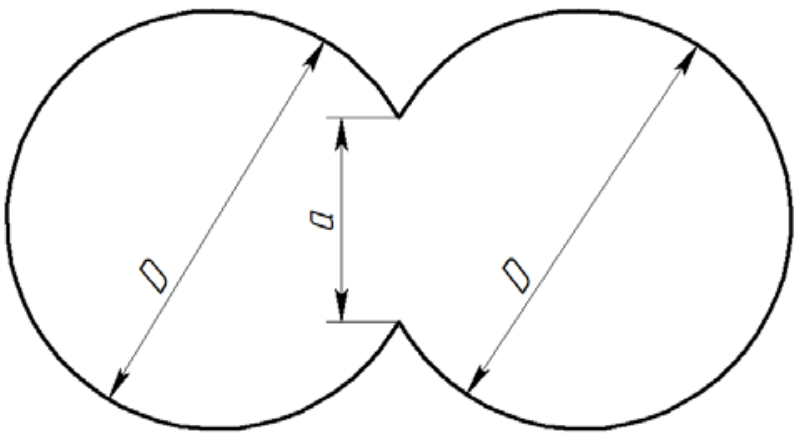

Fig. 2. Coalescence of two spherical particles of diameter D with formation of a neck of diameter a.

According to predictions made in Ref. 1, the 1 aser radiation is ab sorbed on the surface of the $t$ arget. This gives a heat flux through p lane $z=0$ with the density distribution equal to the energy density flux in the crosssection of the laser beam [3]:

$$
q_{0}=P_{0} \cdot \exp \left(-r^{2} / r_{0}{ }^{2}\right) /\left(\pi \cdot r_{0}^{2}\right)
$$

where $P_{0}$ is the absorbed power of the laser beam, $r_{0}$ its nominal radius, and $r^{2}=x^{2}+y^{2}$.

Also this model considers heat losses from sample's surface due to evaporation. The Model proposes evaporation s peed as function of surface $t$ emperature, boiling $\mathrm{p}$ oint $T_{b}$, la tent $\mathrm{h}$ eat o fe vaporation $Q_{b}$ and vapour molecular mass. Heat losses on evaporation can be evaluated the mass loss multiplied with the latent heat of evaporation. [3].

All n ecessary parameters are shown in Table 1 [2],

Table 1. Calculation parameters.

\begin{tabular}{|c|c|c|}
\hline Name & Letter & Value \\
\hline Boiling point & $T_{b}$ & $3223 \mathrm{~K}$ \\
\hline Latent heat of evaporation & $Q_{b}$ & $9.6 \mathrm{MJ} / \mathrm{kg}$ \\
\hline Porosity & $\varepsilon$ & 0.4 \\
\hline Mean coordination number & $N$ & 7.1 \\
\hline Particle diameter & $D$ & $20 \mu \mathrm{m}$ \\
\hline Solid phase thermal conductivity & $\lambda_{s}$ & $2.2(\mathrm{~W} / \mathrm{m} * \mathrm{~K})$ \\
\hline Layer thickness & $h$ & $0.2 \mathrm{~mm}$ \\
\hline Volumetric specific heat & $C_{p}$ & $2.68 \mathrm{MJ} /\left(\mathrm{m}^{3} \mathrm{~K}\right)$ \\
\hline
\end{tabular}

\subsection{Experiment}

In this $\mathrm{w}$ ork, $\mathrm{w}$ e $\mathrm{m}$ ade experiments with silica $\mathrm{g}$ lass powder with fraction 80-100 microns. The substrates are plates of q uartz g lass T U-21RSFSR-644-83 with n onpolished surface of thickness $5 \mathrm{~mm}$.

Laser $\mathrm{CO}_{2}$ source provides 10.6 micron wavelength in continuous mode which quartz absorbs. The source is integrated in co mmercial en graving machine Q ualitech 203 mini. Also, a heater is integrated by our team in this machine. The scheme of the experimental setup is shown in Fig. 3 laser beam $2 \mathrm{f}$ rom s ealed $\mathrm{C} \mathrm{O}_{2}$ tube $1 \mathrm{i} \mathrm{s}$ deflected by fixed mirror 3 and moving mirror 4 that is 
standing on the support moving at $\mathrm{X}$ axis. Laser he ad 5 moves a long $t$ his $\mathrm{r}$ ail i $\mathrm{n} \mathrm{Y} d$ irection. $\mathrm{T}$ he 1 aser he ad contains a mirror at the top and a $\mathrm{ZnSe}$ lens of 2 inches focal le ngth on the bottom. Target 6 is mounted in the heater $7 \mathrm{f}$ or $\mathrm{m}$ aking samples p reheat. Metallographic microscope Olympus BX51M is used for getting photos of samples.

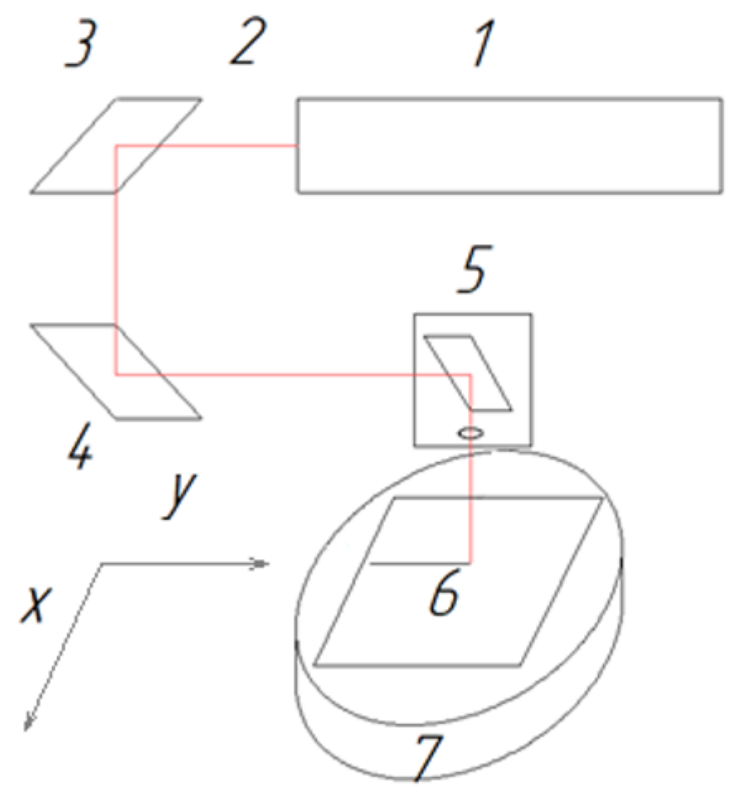

Fig. 3. Principal scheme of laser en graving machine Qualitech 203 mini.

\section{Results and discussion}

Figure 4 presents the results of calculation. As we $\mathrm{c}$ an see, the heat affected zone in SLM often become bigger than the powder layer thickness. Thereby, powder sinters with $\mathrm{t}$ he $\mathrm{p}$ revious $\mathrm{l}$ ayer. $\mathrm{H}$ owever, us ing o nly $\mathrm{l}$ aser processing is s ometimes not enough for g ood sintering with the substrate. Preliminary heating of the sample is perspective $f$ or a ttaining high $\mathrm{c}$ onsolidation. F igure 5 shows comparative results of the consolidation degree.

A s o ne can see, the influence of p reheat is not o nly elevated temperatures, it is also a better sintering due to the d ecreasing of $v$ iscosity with temperature. However, we can also try to predict more effective parameters of scanning. In our case, other parameters such as the layer thickness, the scanning speed and the beam power can be changed
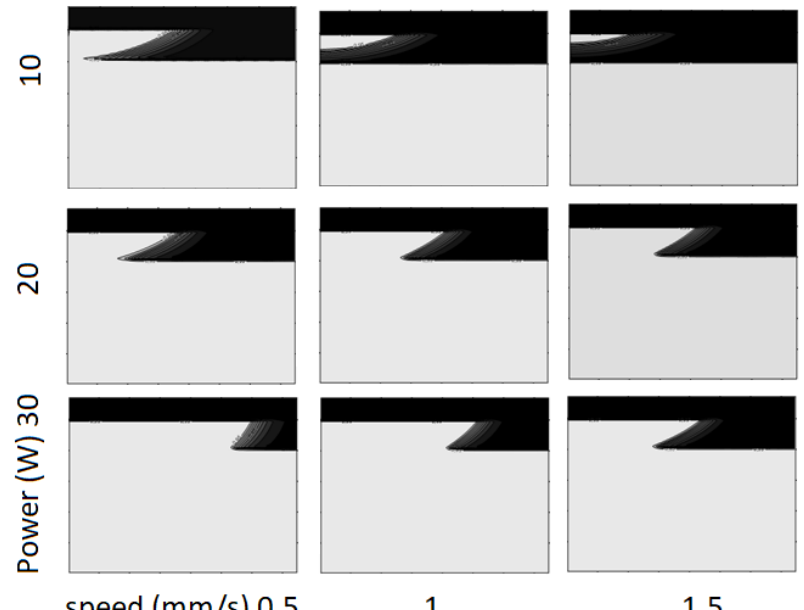

speed $(\mathrm{mm} / \mathrm{s}) 0.5$

1.5

Fig. 6. Comparative results of modelling consolidation degree (white means $\xi>0.9$ ) of nine different situations with have different changing parameters: from top to bottom power changes from 10 to $30 \mathrm{~W}$, from left to right scanning speed changes from 0.5 to $1.5 \mathrm{~mm} / \mathrm{s}$. Ambient temperature is $1100 \mathrm{~K}$.

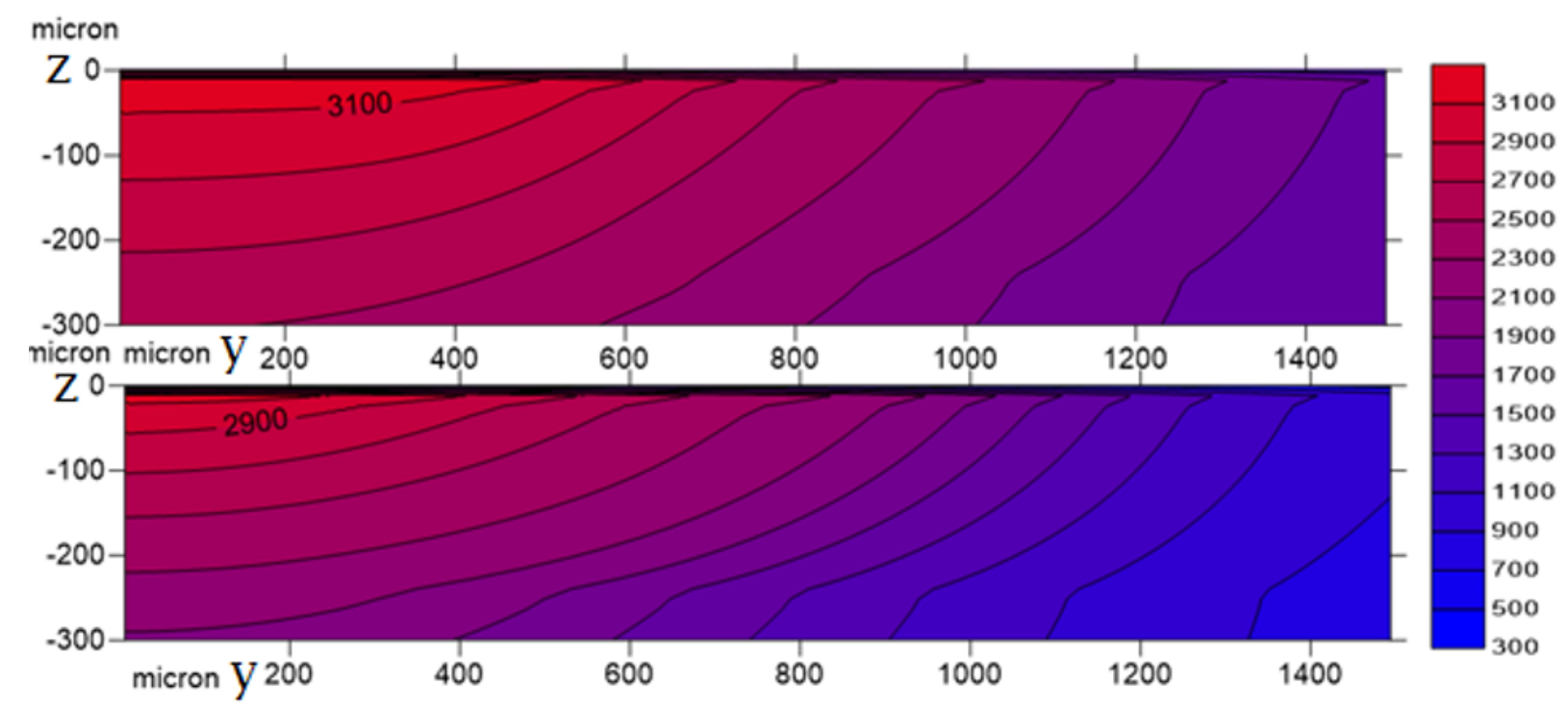

Fig. 4. Distribution of the maximum temperature $(\mathrm{K})$ attained in the transversal cross section $(\mathrm{YZ})$ for the modeled processes of laser melting of glass. On the top, processes modeled with ambient temperature $=1100 \mathrm{~K}$. Below, ambient temperature $=300$ 


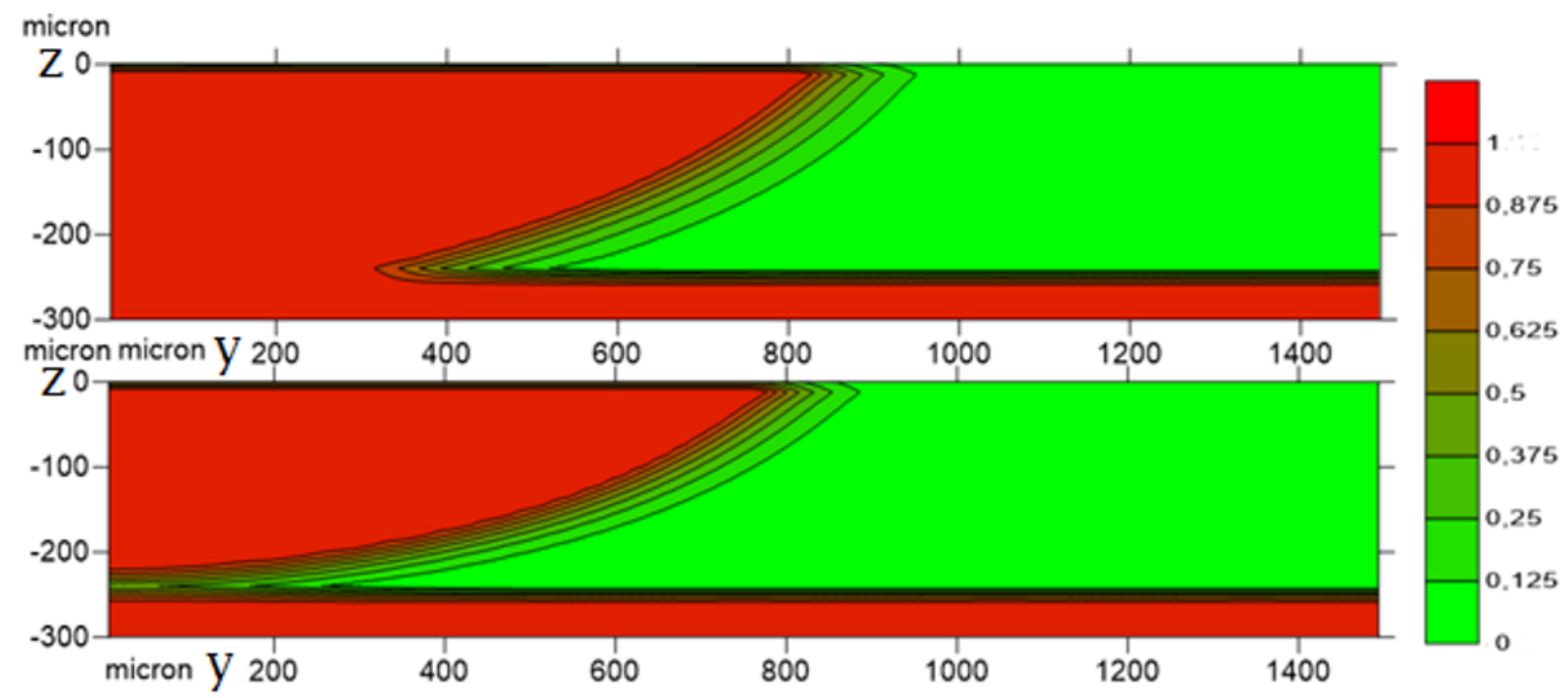

Fig.5. Sintering degree $(\chi 2)$ for the modeled processes of laser melting of glass. On the top, ambient temperature $=1100 \mathrm{~K}$. Below, ambient temperature $=300 \mathrm{~K}$.

Figure 6 shows the influence of changing the scanning speed and beam power. The $10 \mathrm{~W}$ beam power cannot be used in o ur cas e b ecause it gives b ad sintering results, but we can use 20 or $30 \mathrm{~W}$ and the difference there is not as big as between 10 and $20 \mathrm{~W}$. We can al so see that scanning speed influence is bigger for $30 \mathrm{~W}$ laser power. We can make conclusion that $30 \mathrm{~W}$ and $0.5 \mathrm{~mm} / \mathrm{s}$ is the most effective mode.

After g etting modelling results, we made s ome experiments with fused silica powder according to them. Figure 7 presents sintering tr acks. Figures 8 and 9 present cross section of these tracks.

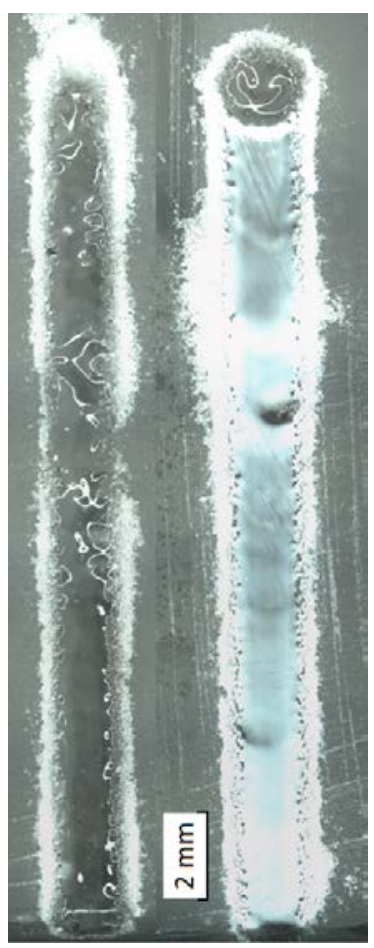

Fig. 7. Top view of the tracks made at scanning speed $=1$ $\mathrm{mm} / \mathrm{s}$ and power $=20 \mathrm{~W}$ (left) and $30 \mathrm{~W}$ (right), preheat temperature $1100 \mathrm{~K}$, layer thickness 200 microns.

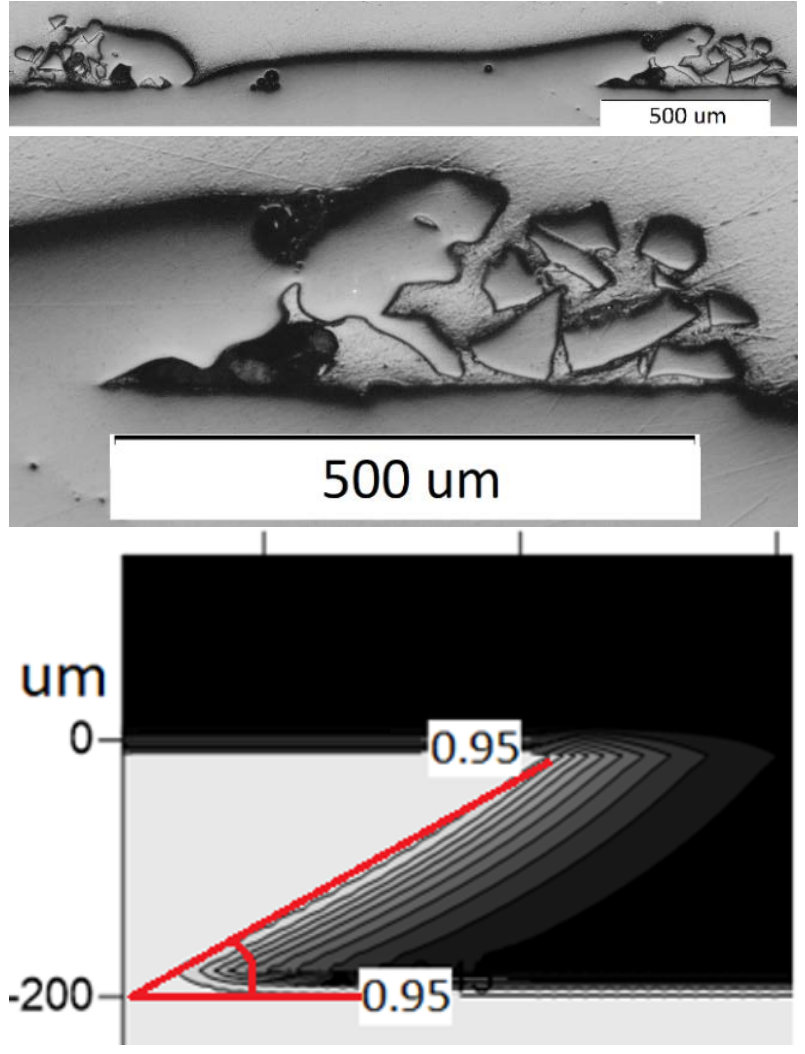

Fig. 8. Cross section of tracks made at $1 \mathrm{~mm} / \mathrm{s} 20 \mathrm{~W}$ (on the top) same zoomed track (in the middle) and the modelling (on the bottom). The red lines show the angle between the substrate and the consolidation border.

As o ne ca $\mathrm{ns}$ ee in Figs. 8 and 9 , th is c alculation method works even with elevated temperatures. At $20 \mathrm{~W}$ beam power, we can see similar angle between substrate and sintered material in calculations and in experiments. At $30 \mathrm{~W}$ beam power, we also can see this angle. The angle between $\mathrm{t}$ he $\mathrm{s}$ ubstrate a nd $\mathrm{c}$ onsolidation bor der increases when power increases. 

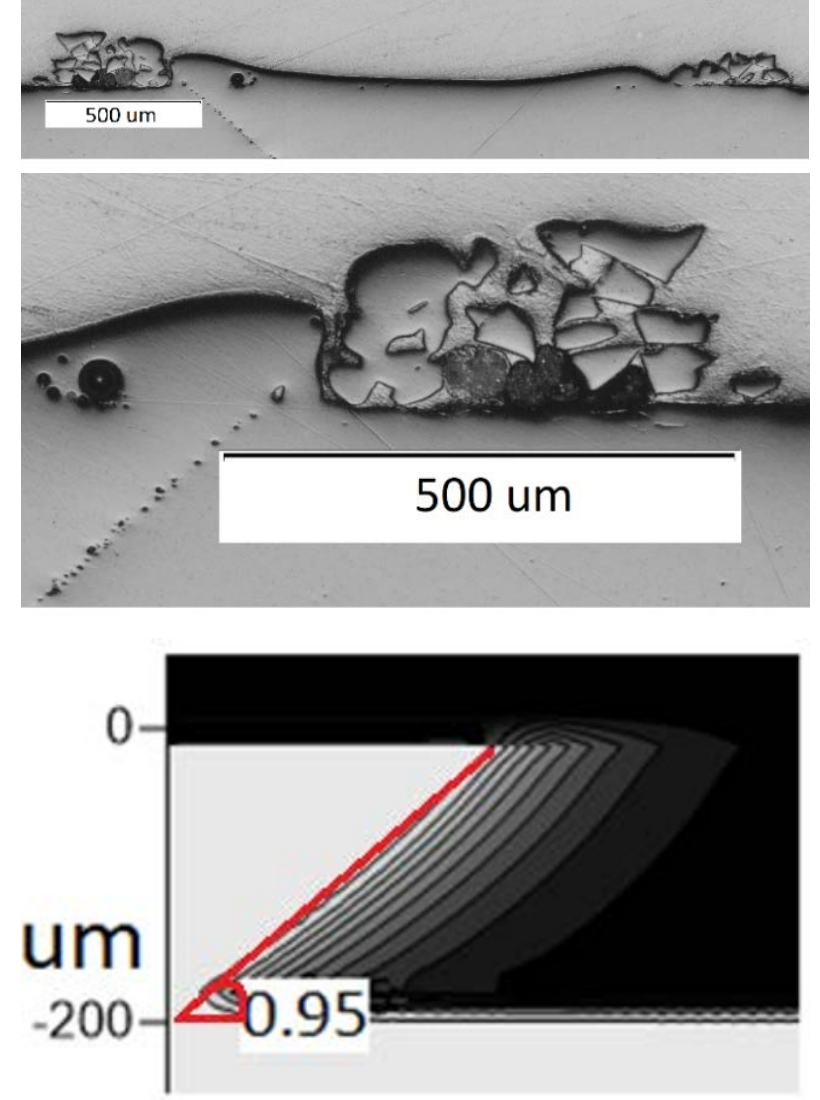

Fig. 9. Cross section of tracks made at $1 \mathrm{~mm} / \mathrm{s} 30 \mathrm{~W}$ (on the top) same zoomed track (in the middle) and his modelling (on the bottom). The red lines show the angle between the substrate and the consolidation border.

Also a t $30 \mathrm{~W}$ w e p redict th at we $\mathrm{g}$ ot $\mathrm{v}$ isible cristobalite (turbid track in Fig.7. right) because in [10] authors $\mathrm{s}$ how $\mathrm{r}$ esults o fq uartz $\mathrm{c}$ rystallization with transformation $\mathrm{i}$ nto $\mathrm{c}$ rystobalite $\mathrm{e}$ xperiments a nd describe it [10]. It cannot be tridymite because the used silica $g$ lass $\mathrm{p}$ owder is $\mathrm{c}$ lean [11]. Ge tting c rystobalite means $\mathrm{t}$ hat we $\mathrm{r}$ eached $\mathrm{t}$ emperature $\mathrm{ab}$ ove the crystallization o ne for a time interval enought $o$ crystallization [10]. The preheating temperature must be lower $t$ han $t$ he glass $t$ ransition $t$ emperature, $o$ therwise glass will $\mathrm{n}$ ot form a fter c ooling the melt o btained b y laser $\operatorname{tr}$ eatment. $\mathrm{L}$ aser $\mathrm{h}$ eating o $\mathrm{fg}$ lass in the crystallization interval must b e for a short te rm, otherwise the glass will devitrify. The numerical values of the characteristic temperatures are shown in Table 2. The preheat temperature $1100 \mathrm{~K}$ used in this work is less than both $\mathrm{t}$ he gl ass $\mathrm{t}$ ransition $\mathrm{t}$ emperature a nd $\mathrm{t}$ he minimum crystallization temperature. However, the laser treatment results in formation of a h eat affected zone in the $p$ eriphery o $f t$ he 1 aser-interaction zo ne where $t$ he temperature is within the crystallization range (see Fig. 4). This may in itiate c rystallization o bserved a s turbid domains in Fig. 7.

\section{Conclusions}

A mathematical model i s pr oposed t o de scribe interdependent $\mathrm{p}$ rocesses of heat $\mathrm{t}$ ransfer an $\mathrm{d} p$ owder consolidation at selective laser melting (SLM) of quartz glass. $\mathrm{T}$ he model i s validated by $\mathrm{c}$ omparison with experiments o $\mathrm{n}$ formation o f $\mathrm{s}$ ingle $\mathrm{t}$ racks. $\mathrm{N}$ umerical calculations indicate $\mathrm{t}$ hat $\mathrm{t}$ he $\mathrm{p}$ reheating accel erates powder c onsolidation. $\mathrm{T}$ his $\mathrm{r}$ esult is in li ne with experiments. $\mathrm{T}$ hus, $\mathrm{t}$ he $\mathrm{p}$ reheating is favourable $\mathrm{t} o$ increase $t$ he $p$ roductivity of S LM a nd t $o$ i mprove $t$ he quality o $\mathrm{ft}$ he material. $\mathrm{H}$ owever, $\mathrm{q}$ uartz glass $\mathrm{c}$ an crystallize at a too high preheat temperature.

Table 2. Temperatures of glass transition and crystallization.

\begin{tabular}{|c|c|c|}
\hline Name & Value & Ref. \\
\hline Glass transition temperature & $1475 \mathrm{~K}$ & 3 \\
\hline Crystallization interval & $1273-1923 \mathrm{~K}$ & 10 \\
\hline
\end{tabular}

This work was supported by the Russian Science F oundation, grant \#20-79-00274.

\section{References}

1. D. Zhang, $\mathrm{X}$. Liu, J . Qiu, Frontiers o f Optoelectronics, $1 \quad-15$ (2020) https://doi.org/10.1007/s12200-020-1009-z

2. R.S. Khmyrov, S .N. Grigoriev, A. A. Okunkova, A.V. Gusarov, Physics Procedia, 56, 345-356 (2014) https://doi.org/10.1016/j.phpro.2014.08.117

3. C.E. Protasov, R. S. Khmyrov, S .N. Grigoriev, A.V. Gusarov, International J ournal o $\mathrm{f} \mathrm{H}$ eat an $\mathrm{d}$ Mass T ransfer, 104, 665 -674 ( 2017) https://doi.org/10.1016/j.ijheatmasstransfer.2016.08.1 07

4. F. Klocke, A . McClung, C . Ader, I n 2004 International Solid Freeform Fabrication Symposium (2004) http://dx.doi.org/10.26153/tsw/6986

5. J. Luo, H. Pan, E.C. Kinzel, Journal of Manufacturing S cience a nd E ngineering, 136(6) (2014) https://doi.org/10.1115/1.4028531

6. R.S. Khmyrov, C .E. Protasov, S .N. Grigoriev, A.V. Gusarov, The I nternational J ournal o $\mathrm{f}$ Advanced M anufacturing T echnology, 85, 1461 1469 (2016) https://doi.org/10.1007/s00170-015-8051-9

7. A.V. Gusarov, M . Pavlov, I . Smurov, Physics Procedia, 12, 248 -254 ( 2011) https://doi.org/10.1016/j.phpro.2011.03.032

8. R.H. Doremus, Journal of Applied P hysics, 92(12), 7619-7629 (2002) https://doi.org/10.1063/1.1515132

9. Q. Liu, Y . Danlos, B . Song, B . Zhang, S . Yin, H. Liao, Journal of Materials Processing Technology, 222, $61 \quad-74$ ( 2015) https://doi.org/10.1016/j.jmatprotec.2015.02.036

10. A.I. N epomnyschih, A .A. Shalaev, T .Y.S izova, A.S. Palkin, A .N.S apozhnikov, L .A. Pavlova Starting te mperature a nd kinetics of crystallisation quartz glass, Crystallography, 63, 314-319 (2018) 
11. P.J. Heaney, D. R. Veblen, J .E. Post, American Mineralogist, 79(5-6), 452-460 (1994) 